\title{
PELOS CAMINHOS DA MEMÓRIA: A REMEMORAÇÃO EM RAKUSHISHA, DE ADRIANA LISBOA
}

\author{
Mirian Cardoso da Silva
}

Submetido em 24 de maio de 2018.

Aceito para publicação em 26 de outubro de 2018.

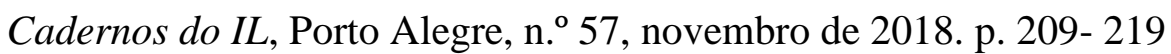

\section{POLÍTICA DE DIREITO AUTORAL}

Autores que publicam nesta revista concordam com os seguintes termos:

(a) Os autores mantêm os direitos autorais e concedem à revista o direito de primeira publicação, com o trabalho simultaneamente licenciado sob a Creative Commons Attribution License, permitindo o compartilhamento do trabalho com reconhecimento da autoria do trabalho e publicação inicial nesta revista.

(b) Os autores têm autorização para assumir contratos adicionais separadamente, para distribuição não exclusiva da versão do trabalho publicada nesta revista (ex.: publicar em repositório institucional ou como capítulo de livro), com reconhecimento de autoria e publicação inicial nesta revista.

(c) Os autores têm permissão e são estimulados a publicar e distribuir seu trabalho online (ex.: em repositórios institucionais ou na sua página pessoal) a qualquer ponto antes ou durante o processo editorial, já que isso pode gerar alterações produtivas, bem como aumentar o impacto e a citação do trabalho publicado.

(d) Os autores estão conscientes de que a revista não se responsabiliza pela solicitação ou pelo pagamento de direitos autorais referentes às imagens incorporadas ao artigo. A obtenção de autorização para a publicação de imagens, de autoria do próprio autor do artigo ou de terceiros, é de responsabilidade do autor. Por esta razão, para todos os artigos que contenham imagens, o autor deve ter uma autorização do uso da imagem, sem qualquer ônus financeiro para os Cadernos do IL.

\section{POLÍTICA DE ACESSO LIVRE}

Esta revista oferece acesso livre imediato ao seu conteúdo, seguindo o princípio de que disponibilizar gratuitamente o conhecimento científico ao público proporciona sua democratização.

http://seer.ufrgs.br/cadernosdoil/index

Quinta-feira, 22 de novembro de 2018. 


\title{
PELOS CAMINHOS DA MEMÓRIA: A REMEMORAÇÃO EM RAKUSHISHA, DE ADRIANA LISBOA
}

\author{
THROUGH THE PATHS OF MEMORY: \\ REMEMBRANCE IN RAKUSHISHA, BY ADRIANA \\ LISBOA
}

Mirian Cardoso da Silva ${ }^{71}$

\begin{abstract}
RESUMO: Trauma e melancolia são termos que acompanham o luto juntamente às lembranças que, por sua vez, podem ser usadas pelo individuo para rememorar acontecimentos. Na obra Rakushisha (2007), de Adriana Lisboa, estados de angústia são desencadeados por meio do exílio e por um processo de perda afetiva e morte, que emergem na memória da personagem Celina, impelindo-a a uma busca de si mesma. Tais memórias servem para possibilitar que a protagonista vivencie um reencontro com suas dores e comece a reconfigurar sua(s) identidade(s) em meio a solidão. Assim, este trabalho tem por objetivo estudar como ocorre o processo da rememoração no romance de Adriana Lisboa.
\end{abstract}

Palavras-chave: Memória, Solidão, Construção de Identidades, Rakushisha.

ABSTRACT: Trauma and melancholy are terms that accompany mourning along with memories, which in turn can be used by the individual to remember events. In Adriana Lisboa's Rakushisha (2007), states of anguish are triggered through exile and a process of emotional loss and death, which emerge in the memory of the character of Celina, impelling her towards a search for herself. Such memories serve to enable the protagonist to experience a reunion with her pain and begin to reconfigure her identity(ies) in the midst of loneliness. Thus, this work aims to study how the remembrance process occurs in Adriana Lisboa's novel.

Keywords: Memory, Loneliness, Construction of Identities, Rakushisha.

\section{O trilhar solitário pelo caminho da memória}

Na obra de Adriana Lisboa, Rakushisha (2007), o ato de rememorar faz parte do processo de transformação identitária que ocorre com as personagens Celina e Haruki. No romance, a noção de passado surge na possibilidade do hoje, ou seja, a partir do momento presente que há necessidade de recorrer ao passado, não consistindo apenas em saber sobre o mesmo, mas sim em permitir que junto das lembranças apareça a carga afetiva que elas carregam. Este movimento permite as memórias serem ponto de partida para os protagonistas pensarem as ações no presente, acarretando uma profunda solidão e introspecção de ambas partes, a princípio de forma não intencional, mas aos poucos, conforme se deslocam e enfrentam suas angústias, tornam-se cada vez mais conscientes de que estão realizando um processo enquanto sujeitos em busca de suas identidades.

O romance Rakushisha aborda as buscas e os anseios de Celina, uma carioca que sofre com a perda da filha, assim como de Haruki, descendente de japonês. Eles se conhecem em um metrô do Rio de Janeiro e, sem perspectivas nem projetos iniciais,

\footnotetext{
${ }^{71}$ Doutoranda em Letras, área de concentração Estudos Literários - UEM.
} 
movidos apenas pelo desejo de outro lugar, eles empreendem uma viagem ao e pelo Japão.

Essa viagem (re)significa o olhar dos protagonistas ao passado, pois a memória tem a capacidade de exercer uma ação que busca preservar algumas informações e "remete-nos em primeiro lugar a um conjunto de funções psíquicas, graças às quais o homem pode atualizar impressões ou informações passadas, ou que ele representa como passadas" (LE GOFF, 1994, p. 423). O lembrar, portanto, se constrói sobre uma percepção sempre presente.

Nesse sentido, dispor da narração para contar o passado é um processo que emerge ao se fazer necessário lidar com um conflito no presente. A memória narrada, por sua vez, se presentifica na ação de relembrar, e o narrador percebe a importância do exercício da rememoração para determinar, modificar, repensar a si e a suas ações no agora, ou seja, busca "reconstruir um conjunto de lembranças de modo a reconhecê-lo." (HALBWACHS, 1990, p. 25).

$\mathrm{O}$ exercício da memória, portanto, é intrínseco à ideia de aprendizagem em Rakushisha, na medida em que é um exercício realizado pela protagonista Celina na tentativa de se reconciliar com pendências do passado, enquanto Haruki percebe que, embora descendente de japonês, nunca havia se interessado pelo passado e pela cultura de sua família. Esse ato de rememorar os fatos é uma ação solitária em que ambos buscam, nas imagens do passado, lembranças capazes de lhes permitir entender seu presente; afinal, é o passado que "contém o acervo de dados, o único que possuímos, o tesouro que nos permite traçar linhas a partir dele, atravessando o efêmero presente em que vivemos, rumo ao futuro" (IZQUIERDO, 2002, p. 9).

Celina recorre à memória, que é exteriorizada pela personagem por meio do diário que escreve, conforme se encontra em meio à dispersão das multidões de Kyoto. No diário, seu foco é comunicar uma experiência pela qual passou, registrar suas memórias, analisar o que viu, vivenciou, descobriu. É uma das formas da escrita de si, que, de acordo com Foucault (2006), era entendida como meio de organizar, de dar coerência para questões internas do indivíduo, visto que as ideias fragmentadas são recolhidas a partir da escrita pessoal que caracteriza o diário. É uma reelaboração do indivíduo, que busca "constituir a si mesmo como sujeito de ação racional pela apropriação, a unificação e a subjetivação, de um já-dito fragmentário e escolhido". (FOUCAULT, 2006, p. 640).

Por meio dos diários, a narrativa constitui a volta ao passado como o centro das ações, em busca de repensar o presente e a si mesma, suas identidades e angústias. É por meio dessa escrita do eu e, também, do narrador onisciente, pois a narrativa oscila entre estes dois pontos de vista, que o/a leitor/a se inteira sobre o passado da personagem: "Seis anos antes, a dor apareceu na sua vida como um monstro saltando do armário. $\mathrm{O}$ jacaré escondido debaixo da cama, que poderia morder sua mão, se a deixasse fora do lençol” (LISBOA, 2007, p. 129). Tal monstro saltando do armário são as lembranças da morte da filha que a princípio ela tenta evitar e que converte a viagem inesperada ao Japão em um caminho solitário de deslocamento interior da protagonista.

Na obra Luto e Melancolia (1917), Freud defende que algumas características da melancolia são parecidas com o processo de luto. Para ele, luto é como o sujeito reage diante da perda de um ente querido, que envolve sério distanciamento do que é tido como normal na rotina do enlutado, e que é superado depois de um determinado tempo. $\mathrm{O}$ luto pode ser profundo, pois

a reação à perda de alguém que se ama, encerra o mesmo estado de espírito penoso, a mesma perda de interesse pelo mundo externo na medida em que este não evoca esse alguém, a mesma perda da capacidade de adotar um novo 
objeto de amor (o que significaria substituí-lo) e o mesmo afastamento de toda e qualquer atividade que não esteja ligada a pensamentos sobre ele. (FREUD, 1917, s/p).

Este decurso é necessário para que o sujeito, ao concluir o trabalho de luto, tenha seu ego novamente livre. Tendo a morte enquanto catalisadora da angústia de Celina, seus constantes deslocamentos pela cidade de Kyoto, guiada pelos haicais do poeta Matsuo Bashô, acabam por aumentar a sua melancolia, pois é durante os mesmos que ela percebe que, depois de seis anos, ainda não conseguira completar o processo de luto. Emerge, então, uma personagem em crise que, a partir da memória, busca compreender a fragmentação de suas dores em busca de suas identidades pós-trauma.

O trauma, por sua vez, representa uma experiência que desarticula o estado estável da personagem, criando fissuras em sua existência, as quais, dependendo do grau do trauma, são difíceis de serem controladas ou até impossíveis de serem plenamente sanadas (LACAPRA, 2001). As memórias da filha e a relação desfeita com o marido, a quem culpava pela morte da menina, vão matizar as angústias da protagonista de Rakushisha. Nesse processo que envolve o luto e a melancolia, emerge a consciência de solidão e vazio, levando-a a confrontar sua existência diante da fatalidade da morte.

Há de se considerar, portanto, que a recordação do passado é um processo importante no percurso de luto como também para a (re)construção identitária da protagonista, "pois sem a recordação do passado seríamos incapazes de afirmar nosso lugar no mundo" (IZQUIERDO, 2002, p. 19). Partindo deste viés, o processo pelo qual passa a personagem Celina, ao descortinar o passado, retomando a memória e reavaliando suas angústias, faz-se necessário para que ela seja capaz de se reconciliar com o presente. A dor da perda desencadeia na personagem uma melancolia, um sentimento de falta e ausência, que reflete no seu exterior: "Ter rompido os elos, os laços, tudo aquilo que conduzia a ele. Menos a mágoa. Celina chegou aos 49 quilos. Em volta dos olhos dois círculos negros de resistência, resistência feroz ela não sabia exatamente a quê" (LISBOA, 2007, p. 116).

O luto, portanto, é a memória traumática que requer da personagem um trabalho de rememoração, buscando reconciliar as lembranças que causam a angústia, para então ocorrer uma superação do mesmo. A dor da perda abala as estruturas da personagem, que perde a vontade de acreditar na existência de algo além do sofrimento pelo qual passou, e procura sempre mascará-lo, disfarçar seu eu desestabilizado, em tom melancólico:

Os pés levavam Celina, seu corpo quebradiço, como se numa longa viagem
da sala ao quarto ao banheiro à sala e à porta da varanda que emoldurava o
grande canino de pedra. [...] Celina sabia que o peso secretamente só tinha
trocado de lugar [...] não era um peso de ossos, músculos, vísceras, gordura.
Era um peso de peso. De essência. A balança podia dizer 49 quilos: a balança
não entendia nada de peso. Ali dentro do estômago estavam pelo menos
outros tantos, multiplicados por cem. (LISBOA, 2007, p. 117).

A rememoração, como já dito, ocorre de forma inconsciente, uma vez que as lembranças são engatilhadas por sutilezas do dia-a-dia, durante os deslocamentos da personagem: "Encaminhava-se para a estação de metrô. Então seu telefone celular tocou dentro da bolsa, e foi um toque capaz de tirar o planeta do eixo por um segundo" (LISBOA, 2007, p. 131, grifo nosso). O toque de celular é um meio para acionar a memória da personagem por ter sido assim que soubera do acidente da filha e do exmarido. A narrativa é aos poucos construída de modo a despertar em Celina um 
reencontro com o passado que seja capaz de permitir-lhe uma reconstrução identitária e o perdão ao ex-marido, com quem desfaz os laços:

\begin{abstract}
Ali ela desfez os elos, os laços, tudo aquilo que conduzia a ele. Menos a mágoa. Pois se ele era o culpado, que estava ao volante, que se distraiu ou cochilou ou fez uma manobra malfeita - não importava. Todos os caminhos se fecharam. Cresceu mato. $\mathrm{O}$ asfalto, em desuso, rachou.

Mas o toque do celular, um toque simples, telefônico (nada de emulações de sinfonias de Mozart) reverberou para sempre.

Continua reverberando aqui, entre os monumentos de pedra do jardim da Rakushisha. Isso é um fato. (LISBOA, 2007, p. 186-7).
\end{abstract}

A morte e os laços desfeitos que levaram a personagem a se encontrar em meio à melancolia e a um luto não superado, mesmo depois de alguns anos, transformam a perspectiva de futuro ou presente, os quais não eram mais observáveis por Celina, pois o trauma da morte da filha destrói a perspectiva de futuro da personagem:

\footnotetext{
Nada de amanhã é um outro dia. E nada de o tempo passa, não havia mais um de agora em diante, não existia nenhum tipo de projeção para além do instante exato daquela batida do coração. O futuro não existia mais. $O$ passado sim, embora fosse esfumaçado e móvel. Mas o futuro não. (LISBOA, 2007, p. 29)
}

Embora tenha assumido o compromisso de uma viagem inusitada que poderia abrir-lhe os caminhos do passado, a protagonista concebe como medida preventiva evitar o contato com tais lembranças, na intenção de preservar-se da dor: "jamais permitir que a dor doa. Esse é o grande engodo. Minha dor é minha: marca na pele, feito a vermelhidão da queimadura." (LISBOA, 2007, p. 128). Tal fato remete à questão do esquecimento, visto que "nós somos, também, o que resolvemos esquecer" (IZQUIERDO, 2002, p. 10). Para o autor, o processo de "tentar esquecer" é uma ação contínua da memória sobre o fato que se tenta olvidar, pois, ao afirmar que "deve esquecer", o próprio cérebro seleciona quais memórias não se quer lembrar.

Desta forma, o processo acaba por se inverter, visto que as tentativas de esquecimento requerem que as lembranças a serem esquecidas venham à tona. É por esse processo que passa a personagem do romance, pois, ao afirmar o desejo de não deixar que a dor doa, ocorre uma tentativa de impedir que aconteça a rememoração dos acontecimentos e do trauma que é a morte. Contudo, o esquecimento consciente não é capaz de se consumar de fato, mas acaba selecionando as memórias que a protagonista deseja esquecer, colocando-as em evidência.

Celina, nesse sentido, conscientiza-se de que tentar esquecer acaba por ser mais difícil do que lembrar: "Quase tudo era passível de ser esquecido. Muitas outras coisas insistiam em não ser esquecidas. E assim a memória seguia como subalterna do coração." (LISBOA, 2007, p. 172). A consciência desta necessidade de lidar com suas memórias, faz do deslocamento pela cidade de Kyoto, sozinha em meio a uma multidão de pessoas com cultura e língua diferentes da sua, um meio de se isolar em si mesma, percebendo "que não pertence, que não entende, que não fala" (LISBOA, 2007, p. 134). Tal solidão provoca o encontro com as memórias que tentava afastar: "Como era possível não pensar em Alice. Como era possível pensar em Alice, conformar-se em reduzi-la a um pensamento" (p. 174).

Há, portanto, uma frustação das tentativas de esquecimento, que podem ser traduzidas pelas reminiscências do passado que se manifestam na mente da personagem, no presente, através de coisas simples da vida cotidiana: "as coisas que faziam pensar 
em Alice nunca eram volumosas, grandiosas, nunca tinham lustre de trama principal. Ao contrário, eram pequenas, medidas com displicência de cotidiano." (LISBOA, 2007, p. 151). A memória é acionada de forma natural e não intencional, levando-a a um processo de revisão que, segundo Ricoeur (2000), é característico da memória, pois esta não para de trabalhar. O autor utiliza-se do termo "memória exercida" para exemplificar a questão da rememoração, em que corresponde às lembranças impedidas de serem exteriorizadas em razão de algum trauma como, por exemplo, o luto e a perda afetiva.

Algumas lembranças retornam à personagem para incomodar e doer mais que outras. Por mais que incomodem, elas são necessárias no processo de rememorar que "não deve ser entendido apenas como preenchimento de lacunas, recomposição de uma imagem passada [...] mas também enquanto a própria lacuna, enquanto decomposição, rasura da imagem." (CASTELLO-BRANCO, 1995, p. 26). Considerar isso na análise de Rakushisha é admitir que o passado não se conserva intacto e que o debruçar-se sobre as lembranças em busca de aprender a caminhar novamente é um gesto de construir o que ainda não é, o que virá a ser. Ou seja, remete às identidades que a personagem poderá ter ao superar o trauma do passado:

\begin{abstract}
A beira da Lagoa, estavam aqueles três: mãe, pai, filha pequena adormecida no carrinho [...] Tão fácil. Tão assustadoramente fácil, ela pensaria, depois, quando nada mais podia voltar a ser fácil, quando nada mais podia incluir Marco e Alice - e aquela tarde se agarrava à memória como se fosse um insulto. (LISBOA, 2007, p. 66).
\end{abstract}

Toda a tessitura da narrativa, os deslocamentos espaciais e da memória, configuram uma metáfora para o processo de redescobertas e aprendizagem, no seio da solidão da própria viagem interna realiza por Celina. Em ambos os sentidos, a viagem a impele a deixar seu estado passivo e agir em si mesma, buscando respostas para suas questões existenciais, e no ambiente circundante, resolver questões de ordem prática, suscitadas pelo novo contexto espacial, que a convoca a todo instante. Assim é que Celina descobre ser capaz de reaprender a andar e externar sua dor, de forma a conseguir perdoar e compreender a si mesma.

Sua trajetória encerra a noção de que os fatos narrados são presentificados, isto é, os deslocamentos espaciais funcionam como uma metáfora dos deslocamentos interiores, descortinando o passado que, inevitavelmente, a leva a um aprendizado de si. Nesse reencontro dilacerante da personagem com suas memórias relacionadas ao exmarido e à filha, o/a leitor/a tem a sensação de estar acompanhando-a durante o processo, no presente da protagonista: "Estive reaprendendo a andar [...] depois da tempestade, da era glacial, da grande seca, a gente pode usar a imagem que quiser, ninguém vai se importar muito, afinal quem somos nós se não menos do que anônimos aqui." (LISBOA, 2007, p. 12)

Celina, portanto, ao se deparar com um país diferente e com uma língua que desconhece, deixa-se levar pela solidão de ser uma estranha em terra alheia, pois "o estranho está em todo lugar, em todos nós" (LOPES, 2002, p. 178), e, por ser assim, não existir para os outros naquele espaço do Japão permite que Celina se volte para si, para sua trajetória e seus sentimentos. Desvela, portanto, o encontro revelador com suas memórias em busca de se estabelecer e/ou (re)construir:

Morrer seria uma espécie de aceitação? Seria compactuar com esse pequeno núcleo de existência e ir fechando as portas, as comportas, até só restar esse quase nada? E então desistir dele também? Abandoná-lo, mergulhar no nada, no fim, no coisa nenhuma, um estalar dos dedos, plec, e o amontoado de ossos, músculos, vísceras, espaços em branco, corrente elétricas, emoções, 
reações químicas e pensamento que era você, que fingia se reunir sob um nome fantasia. (LISBOA, 2007, p. 160).

É através dessa viagem que ela descobre um meio para que tudo isso possa acontecer, que possa se reconstruir, assumir seu papel de viajante no mundo e juntar seus fragmentos, desvendar suas identidades. Celina conduz a narrativa de forma a tentar ocultar o motivo por estar reaprendendo a andar depois da tempestade, conforme se desvela a narração. O/a leitor/a, todavia, encontra pistas que promovem essa costura entre o presente e o passado da personagem, desvendando as razões da busca, das incertezas e das dores da protagonista: "Se vim para lembrar - se vim para esquecer. Se vim para morrer ou para me vacinar. Talvez eu descubra. Talvez nunca seja possível descobrir, desvelar, levantar o toldo, remover qualquer traço de ilusão da ilusão de caminhar." (LISBOA, 2007, p. 12)

No romance, vemos que Celina se pega sempre questionando o sentido da viagem, o porquê de ter aceitado ir ao Japão com um desconhecido, o que esperava encontrar em um país tão diferente do seu, por que se deslocava dentro de Kyoto, "e se viagem fosse outra viagem" (LISBOA, 2007, p. 125). Isso desvenda o significado da viagem em sua interioridade, não apenas aquela que ocorreu no exterior, fazendo com que ela saísse do Brasil e fosse ao Japão, mas também a que se permite fazer em busca de respostas por questões mais essenciais à existência do ser humano:

\begin{abstract}
Então se fez a quieta revolução dos passos. A senhorinha sentada no sofá avisou que não ia embora; pediu um café, um chá, um copo d'água. Celina resolveu servir. E percebeu que bastava isso: tomar cuidado com os passos. Se eles tocassem os lugares certos, todo o resto estaria bem. Transitava pela sala de estar com sua visita a observá-la. Coloca um pé na frente do outro na frente do outro na frente do outro. Servia o café, o chá, o copo d'água. (LISBOA, 2007, p. 129, grifo nosso).
\end{abstract}

A viagem, assim como os deslocamentos consequentes do mundo em transformação constante, constrói sujeitos em crise que, embora moventes, buscam algo a que possam se agarrar, permanecer, pertencer; ou seja, são personagens que desejam algo para chamar de seu, onde consigam repousar seus sentimentos, suas lembranças, suas memórias; Isso pode ser observado no decorrer da história, quando Celina, no apartamento em Kyoto, observa que "o pequeno espaço é uma pequena confluência do mundo também, um palimpsesto de gente que passou, mas quis firmar o atestado de sua passagem numa ou noutra pequena gentileza [...]" (LISBOA, 2007, p. 50).

A protagonista, assim, questiona se "a vida por acaso se faz de reencontros" (LISBOA, 2007, p. 14). Reencontros através da memória e que encontram uma forte sintonia com o espaço exterior e interior, levando-a enfrentar a dor da perda: "A dor. Verdade indesejável num mundo de analgésicos" (LISBOA, 2007, p. 128). Tudo isso acaba por se transformar em uma enorme aflição, a qual ela tenta, desesperadamente, manter no devido lugar, pois, como já mencionado, lhe era importante não permitir que a dor doesse: "Que a dor se cale, se encolha, se submeta, se amordace, se domestique" (LISBOA, 2007, p. 128).

As inquietudes, que são reveladas no íntimo de Celina, ocasionadas pelos espaços labirínticos de solidão e fragmentação, instauram no seu ser deslocado uma inquietante melancolia que "não é só uma sensibilidade constituída a partir da experiência da passagem do tempo, de sua finitude [...] mas se torna adequada à contemporaneidade. O fio condutor é a imagem da viagem" (LOPES, 2002, p.165). Tais inquietações, questionamentos, buscas e solidões desencadeiam a busca pela compreensão de seu papel no mundo: 
Gosto dessa familiaridade da estranheza, de que de repente me dou conta [...]. Qual é o lugar que ocupo no mundo? Tem nome, esse lugar? Tem dimensões?" (LISBOA, 2007, p. 89).

E se for preciso assumir a fragilidade de nós mesmos na fragilidade daquilo que somos juntos? Viajantes? (LISBOA, 2007, p. 182).

Tais questionamentos acabam por possibilitar que Celina consiga lidar melhor com o presente e planejar adequadamente o futuro. Isto a leva a desprender tempo para se encontrar com o passado e repensar suas ações, dores e angústias, uma vez que todos fazem essa viagem "entre o passado, no qual reafirma a identidade ao restabelecer o elo com os ascendentes, o presente, quando afirma suas necessidades, e o futuro, no qual projeta aspirações e esforços." (MORIN, 2004, p. 77).

Nos caminhos pelos quais transita durante o romance, a personagem carrega tais sentimentos e angústias, enquanto deixa que o espaço circundante se constitua como parte da formação de suas identidades, que são móveis exatamente por serem influenciadas pelos constantes deslocamentos que empreende: "Saí para passear com Bashô. Coloquei as folhas soltas dentro da bolsa. Resolvi ir ao Tetsugaku no michi, o Caminho do Filósofo." (LISBOA, 2007, p.83). Estes espaços criam a sensação de forado-lugar, nos termos de Cury (2007), dificultando a reconstituição identitária, e produzindo as identidades fragmentadas e/ou híbridas. Logo, "ela parecia deixar de existir, parecia migrar para alguma outra dimensão, e o que ficava era só um fantasma, um holograma guardando seu lugar." (LISBOA, 2007, p. 38).

Assim, é tecido seus dramas internos, indagando seus sentimentos em relação à mobilidade fluída na qual se perde e, ao mesmo tempo, se busca: "ainda não sei se andar equivale a lembrar, se equivale a esquecer, e qual das duas coisas é meu remédio, se nenhuma delas, se nenhuma opção existe e se andar é o mal e o remédio, o veneno que tece a morte e a droga que traz a cura." (LISBOA, 2007, p. 12).

Aqui, o sentido de viajar não é apenas deslocar-se territorialmente, antes significa sair do lodo imutável da vida, mover-se fora e dentro de si. É transcender e se permitir deslocar da comodidade, assim como faz Celina, que chega à conclusão de que "a viagem sempre é pela viagem em si. É para ter a estrada outra vez debaixo dos pés. [...] É o lugar aonde a viagem decide leva-lo.” (LISBOA, 2007 p. 121). Sendo que, ao pôr os pés na estrada, o indivíduo assume uma responsabilidade que vai da questão cultural até às buscas identitárias e aos questionamentos existenciais. O "talento de viajar", assim, também é se permitir uma autodescoberta, um (re)conhecimento de si, de encarar suas dores e solidões e se descobrir parte do mundo movente, enquanto sujeito dessa mobilidade: "Mesmo os que permanecem, que jamais saem do seu lugar, viajam imaginariamente ouvindo histórias, lendo narrativas, vendo coisas, gentes e signos do outro mundo [...] a viagem revela-se um recurso comparativo excepcional." (IANNI, 2003, p. 14-5).

A busca por compreensão, a volta ao passado e a viagem ao desconhecido Japão, influenciam o que acontece no interior de Celina, transfigura-a para além do sentido de viagem apenas por prazer. $\mathrm{O}$ termo assume, dessa forma, uma metáfora que transcende a busca da personagem e suas identidades:

Gosto dessa familiaridade da estranheza, de que de repente me dou conta. Gosto de me sentir assim alheada, alguém que não pertence, que não entende, que não fala. De ocupar um lugar que parece não existir. Como se eu não fosse de carne e osso, mas só uma impressão, mas só um sonho, como se eu fosse feita de flores e papéis e um tsuru de origami e o eco do salto de uma rá 
dentro de um velho poço ou o eco dos saltos de uma mulher na calçada. (LISBOA, 2007, p. 133-4).

A viagem, desta forma, promove-lhe o reconhecimento de suas identidades múltiplas, a partir desse embate cultural que a desestabiliza e isola: "carros, pessoas e bicicletas, guarda-chuvas e saltos altos se entendiam. Estranha, apenas eu" (LISBOA, 2007, p. 46).

Há, também, no romance, a simbologia da chuva, sendo esta relacionada diretamente com a água, que remete à transformação, purificação, limpeza, cura e força. Em muitas culturas, a água é instrumento para purificação espiritual, por isso é considerada sagrada, é "fonte de vida, meio de purificação, centro de regenerescência", e mergulhar nela "é retornar às origens, carregar-se, de novo, num imenso reservatório de energia e nele beber uma força nova" (CHEVALIER e GHEERBRANT, 2009, p. 15). Além da chuva significar tempo de benção divina, espiritual e fertilidade, pois cai no solo e o fecunda, segundo Junior, há uma "associação entre o corpo e a água (...) quer através da simbologia da água como elemento fundamental para a vida, quer seja pela relação entre a água, umidade e sexualidade" (JUNIOR, 2006, p. 160). A água, portanto, agiria diretamente na sexualidade, conectando-se com a vida.

$\mathrm{Na}$ busca por pensar seu eu em meio à dor, a personagem utiliza-se do termo e sua carga significativa para exemplificar sua angústia:

Como medir a dor? Haveria unidades pessoais? Centímetros cúbicos, milhas, hectares? E a dor passaria? Simplesmente a dor choveria na época certa, que por aqui chamam tsuyu, a estação chuvosa, um pesadelo do início do verão? E depois a umidade da dor evaporaria sob um sol de promessas? (LISBOA, 2007, p. 69, grifos nosso).

Enquanto passa pelo processo de reaprendizagem, a protagonista percebe que ainda não é capaz de externar totalmente sua dor. Tocada pelo trecho do diário de Matsuo Bashô, que diz " $28^{\circ}$ dia Em sonho, evoquei Tokoku, e desperto em lágrimas" (LISBOA, 2007, p. 175), pelo percurso da viagem, em seus deslocamentos na cidade do Japão, ela descobre que as lágrimas não rolavam, que estava na estação seca, e compreende, portanto, que não conseguia chorar: "ao despertar, meus olhos estavam secos" (p. 165; 176; 177; 178); contudo, após realizar o percurso da rememoração, a personagem passa por um processo de purificação:

\footnotetext{
No horizonte, as montanhas perfiladas. A água nos olhos de Celina, que brota vinda de um lugar recém-descoberto, que brota pela vendedora da loja de artesanato em Sagano e pelo aniversário de Alice e por Celina, que não consegue estreitar sombras nos braços, e por Marco, e pelos mortos no campo de batalha, e por Haruki, que neste momento retorna de Tóquio, e por Yukiko, a mulher que Haruki ama, a mulher que ama Haruki. Escorre pelo seu rosto aquela água salgada de uma estação interna das chuvas, sua intima tsuyu, que se inaugura agora. (LISBOA, 2007, p. 180, grifo nosso).
}

Sua tsuyu, a estação das chuvas, aquela que limpa, que lava, que leva, "se inaugura agora". Ao se permitir a viagem ao Japão vivencia uma alteridade capaz de conseguir, finalmente, encontrar na dor e na solidão o perdão necessário para que pudesse se reconhecer em meio a sua perda: "no envelope que o vendedor na bilheteria da Rakushisha lhe dá, escreve o nome de Marco. Pega a folha do caderno que lhe serve de diário e escreve: me desculpa" (LISBOA, 2007, p. 186). Isto ocorre porque "a água apaga a história" e "restabelece o ser num estado novo" (CHEVALIER e GHEERBRANT, 2009, p.18), transbordando o estado emocional da personagem, que 
cai brandamente em seu interior por finalmente ter conseguido superar as perdas, em um estado de paz e cura de suas pendências com o passado.

Ao finalmente aceitar a morte da filha e o vazio que ficou com sua perda, ocorre, portanto, o perdão necessário para sua superação. O perdão é o momento em que as memórias dolorosas são aplacadas e superadas, e "liberta tanto o que perdoa quanto o que é perdoado" (FILHO, 2013, p. 253), é o sentimento necessário para que a personagem seja eximida da posição de vítima das ações que ocasionaram a mágoa. A chuva externa reforça os sentimentos novos da protagonista: "Celina sente a chuva fina que começa a cair enquanto folheia seu diário [...] Enquanto sai da Rakushisha e pega sua bicicleta e olha o campo de arroz e as montanhas perfiladas no horizonte" (LISBOA, 2007, p. 187).

Dessa forma, a viagem externa, feita pela cidade de Kyoto no Japão, impulsiona uma solidão capaz de possibilitar essa viagem interior, pelos caminhos da memória, a fim de reconstruir sua identidade pós-trauma. Possibilita, também, descobrir-se no presente enquanto sujeito capaz de superar a dor da perda, pois, como afirma a personagem: "A viagem nos ensina algumas coisas. Que a vida é o caminho e não o ponto fixo no espaço. Que nós somos feito a passagem dos dias e dos meses e dos anos [...]" (LISBOA, 2007, p. 187). A viagem interior por meio da memória, portanto, é capaz de possibilitar os embates com suas dores e ajudar a lidar com sua perda na tentativa de reconstrução de si.

Como é bastante comum na literatura de autoria feminina contemporânea, a obra não apresenta o clássico happy ending, ao ter um final em aberto, com Celina ainda em Kyoto esperando Haruki voltar de Tóquio. Os sentimentos descobertos são aqueles que finalmente são reconhecidos por ela, como a dor da perda, um luto capaz de desestabilizar seu mundo individual, e o perdão necessário, os quais são reencontrados por meio da imersão na memória. Esses sentimentos são exteriorizados através do diário escrito por ela e pelas lágrimas que descem, influenciados pelo deslocamento, por encontros e desencontros. O romance, assim como tantos outros de autores contemporâneos, acaba por expressar, na metáfora da viagem, a vida enquanto constantes buscas e as (re)descobertas desses sujeitos em crise. Nesse sentido, o mais relevante é a percepção da personagem do que a atormenta a ponto de fazê-la infeliz e incompleta, após finalmente se encontrar diante da aceitação de sua dor.

Os lugares físicos e psicológicos pelos quais ela transita ajudam-na a, finalmente, se aceitar em suas próprias dores e fragmentações, e possibilitam que Celina se abra para suas memórias e, com elas, à dor das perdas que fazem parte da vida, ao enfrentamento diante da morte e da dor, transformando a pergunta do porquê de ter aceito viajar com Haruki em uma resposta que é a própria viagem: um verdadeiro deslocamento na interioridade de Celina, que se descobre e se permite reaprender.

Assim, toda a tessitura da narrativa, as rememorações e os deslocamentos espaciais da personagem, representam uma grande metáfora para o processo de redescobertas e aprendizagem, que se configuram no seio da solidão da própria viagem interna que a protagonista realiza em suas memórias. Em vista disso, Celina descobre ser capaz de reaprender a andar e consegue exteriorizar sua dor, de forma a conseguir o perdão necessário para que pudesse compreender a si mesma. Portanto, a memória, o passado e a rememoração, se configuram como partes importantes nesse processo de reaprendizagem, pois é por intermédio das lembranças que a personagem problematiza seu eu presente, compreende suas angústias e possibilita a busca por reconstrução identitária. 


\section{REFERÊNCIAS:}

BONNICI, Thomas. Teoria e crítica literária feminista: conceitos e tendências.

Maringá: Eduem, 2007.

CASTELlO-BRANCO, Lúcia. A traição de Penélope. São Paulo: Ana Blume, 1995.

CHEVALIER, Jean \&amp; GHEERBRANT, Alain. Dicionário dos Símbolos: (mitos, sonhos, costumes, gestos, formas, figuras, cores, números). Tradução Vera da Costa e Silva. 24. ed. Rio de Janeiro: José Olympio, 2009.

CURY, Lisboa Maria Zilda Ferreira. Cartografias literárias: Tsubame, de Aki Shimazaki e Rakushisha, de Adriana (Universidade Federal de Minas Gerais), 2007. Disponível http://www.revistas.unilasalle.edu.br/index.php/interfaces/article/viewFile/436/304

LACAPRA, Dominick. Writing history, writing trauma. Chicago: Parallax, 2001.

FILHO, Mamede Said Maia. Entre o passado e o presente, a afirmação da memória como direito. 2013. 248 f. Tese (Doutorado em Direito) - Universidade de Brasília Brasilia.

FOUCAULT, M. A ordem do discurso. São Paulo: Ed. Loyola, 1996

FREUD, S. Luto e melancolia. Tradução, introdução e notas de Marilene Carone. São Paulo: Cosac Naify, 2011.

HALBWACHS, Maurice. A memória coletiva. São Paulo: SP. Editora Revista dos Tribunais: 1990.

IZQUIERDO, Iván. Memória. Porto Alegre: Artmed, 2002.

LE GOFF, Jacques. História e memória. Campinas: Ed. Unicamp, 1994. LIBANORI

JÚNIOR, Leite Jorge. Das maravilhas e prodígios sexuais: a pornografia "bizarra" como entretenimento - São Paulo: Annablume, 2006.

LISBOA, Adriana. Rakushisha. Rio de Janeiro: Objetiva, 2014

LOPES, Denilson. A viagem é uma viagem. In: O homem que amava rapazes. Rio de Janeiro: Aeroplano, 2002.

MORIN, Edgar. Os sete saberes necessários à educação do futuro. Tradução Catarina Eleonora F. da Silva e Jeanne Sawaya. São Paulo: Cortez, 2004.

PERES, Urania Tourinho. Uma ferida a sangrar-lhe a alma. In: FREUD, S. Luto e melancolia. Tradução, introdução e notas de Marilene Carone. São Paulo: Cosac Naify, 2011.

RICOEUR, Paul. A memória, a história, o esquecimento. Trad. Alain François et al. Campinas, SP: Editora da Unicamp, 2007. 